\title{
The Relations Between Maternal Meta-Emotion Philosophy, Child Interpersonal Problem Solving, and Peer Competence
}

\author{
Ranyi Choi ${ }^{1}$, Eunyoung Nahm ${ }^{2}$ \\ Department of Child Psychology, Seoul Women's University, Seoul, Korea ${ }^{1}$ \\ Department of Child Studies, Seoul Women's University, Seoul, Korea ${ }^{2}$

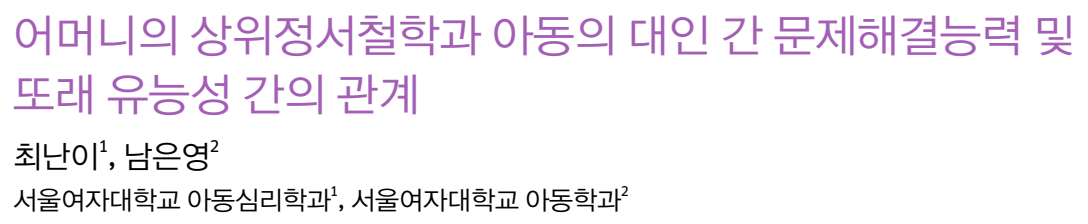

Objective: This study examined the relations between maternal meta-emotion philosophy, child interpersonal problem solving, and peer competence among children aged 4-5 and their mothers and teachers.

Methods: A total of 54 children from 24 kindergartens were assessed on their interpersonal problem solving and peer competence. Their mothers reported on meta-emotion philosophy. Their teachers were assessed on child peer competence.

Results: The major findings of this study were as follows. First, maternal meta-emotion philosophy, child interpersonal problem solving, and child peer competence showed positive correlation patterns. Second, child interpersonal problem solving and peer competence was found to be influenced by maternal child-directed meta-emotion philosophy but not by maternal self-directed meta-emotion philosophy.

Conclusion: Findings highlight the importance of maternal meta-emotion philosophy and that their emotion socialization play a significant role in identifying the mechanisms leading to child social cognitive ability and social adjustment. Furthermore, these results could lead to important basic studies in developing parent/teacher education programs.

Keywords: maternal meta-emotion philosophy, interpersonal problem solving ability, peer competence, parent-child emotional relationship

\begin{abstract}
서론
부모와 자녀 간의 정서적 상호작용은 자녀의 성장에 필요한 다양한 발달을 촉진시킨다. 최근 주 양육자의 정서 관련 태 도가 아동의 구체적인 행동 발달로 연결되는 기제를 밝히기

Corresponding Author: Eunyoung Nahm, Department of Child Studies, Seoul Women's University, Hwarang-ro, Nowon-gu, Seoul, Korea.

E-mail: nahmey@swu.ac.kr
\end{abstract}

위한 연구가 이루어짐에 따라 정서에 관한 가치관 및 신념을 의미하는 '상위정서철학'이 Gottman, Katz와 Hooven (1996, 1997)에 의해 소개되었다. 상위정서철학이란 정서에 대한 느 낌과 태도들을 포함하는 상위 인지적 개념으로써, 정서적 행 동에 대한 실행 기능을 수행하며 부모의 상위정서철학은 어머

(C)The Korean Association of Child Studies

This is an Open Access article distributed under the terms of the Creative Commons Attribution Non-Commercial License (http:// creativecommons.org/licenses/by-nc/4.0) which permits unrestricted noncommercial use, distribution, and reproduction in any medium, provided the original work is properly cited. 
니 본인의 정서에 대한 상위정서철학, 자녀 정서에 대한 상위 정서철학인 두 가지 하위요인으로 구성된다. 어머니 본인의 정서에 대한 상위정서철학은 부정적 정서에 대해 어머니가 직 접 느끼고 경험하는 태도를 말하고, 자녀의 정서에 대한 어머 니의 상위정서철학은 일상에서 자녀가 경험하는 부정적 정서 상황에 대해 어머니가 갖는 고유의 인식방식 및 태도를 의미 한다(Gottman et al., 1997).

이는 부모-자녀 관계에서 본인과 자녀가 경험하는 부정적 인 정서에 대해 부모가 어떤 신념을 가지고 있느냐에 따라 자 녀와의 정서적 경험에서 구체적인 양육행동으로 나타나게 되 는데, 본인과 자녀의 정서를 인식하는 정도가 높고 자녀가 느 끼는 정서 경험을 자녀와의 친밀감 형성의 기회로 삼는 부모 들은 자녀에게 허용적인 것으로 드러났다(Nahm, 2006). 또 한 부모의 상위정서철학은 자녀의 정서조절능력, 사회적 기 능, 신체적 기능, 학업 성취와도 관련 있고(Gottman et al., 1997), 아동의 심리적 적응과도 밀접한 연관이 있었다(Katz \& Hunter, 2007; Katz, Maliken, \& Stettler, 2012). 그 밖에 아 동의 내재화 문제 및 외현화 문제와도 관련이 있었다(Shortt Stoolmiller, Smith-Shine, Eddy, \& Sheeber, 2010). 이러한 연구들 은 부모의 상위정서철학이 아동의 심리사회적 결과들에 다양 한 영향을 미치는 중요한 요인임을 함의하는 것으로, 자녀의 발달에 기저를 이루는 부모의 상위정서철학에 대한 중요성이 더욱 증대되고 있음을 보여준다(Stettler \& Katz, 2014).

이에 부모와 자녀 관계에서 보이는 정서적 특성들을 다루 기 위한 연구가 다수 실시되었으나, 대부분 정서의 단일적 부 분에 초점을 맞춘 질문지법을 사용함으로써 대상의 질적인 특 성은 간과할 수 있는 연구방법론적인 한계가 존재한다. 본 연 구는 어머니가 본인과 자녀가 경험하는 정서적 상황에서 무엇 을 중요시하고 어떻게 정서를 생각하며 관점을 두는가를 초점 에 둔 상위정서철학을 심층적으로 분석하여 통제된 질문과 응 답으로 파악하기 어려운 주관적인 정서적 경험을 제공받는데 용이한 면접법을 채택하여 사용하였고 이에 대한 연구는 부 모-자녀의 정서적 관계에 깊은 함의를 제공하리라 생각된다.

한편 어머니의 상위정서철학이 자녀에게 양육행동으로 나 타나 영향을 받게 되는 자녀 관련 변인을 고려할 수 있는데, 부모-자녀 관계는 아동이 사회적 상황 가운데 발생하는 다 양한 갈등을 해결하고 다루는 능력에 영향을 준다(Eisenberg, Cumberland, \& Spinrad, 1998). 즉 아동의 문제해결능력은 성 장과정에서 습득된 사회적 정보를 바탕으로 갈등문제를 해결 해나간다. 특히 아동은 어머니와 자녀 간의 발생하는 정서적 상호작용에서 기본적인 사회적 기술을 학습하게 되며, 사회적
상황을 생각하고 대처하는 과정을 습득하게 된다(Eisenberg et al., 1998).

이 같은 맥락에서 최근에는 대인 간 문제해결이 사회적 장 면에서 얼마나 효율적으로 기능하는지에 따라 개인의 정서적. 사회적 적응수준이 파악된다는 대인 간 문제해결능력의 개념 이 등장했다. Shure (1982)는 아동이 사회적 상황에서 보이는 행동 이전에 갈등상황을 해결하기 위하여 개인이 가지는 고유 의 생각하는 능력이라고 대인 간 문제 해결 전략을 정의했으 며, Webster-Stratton과 Hammond (1997)는 아동이 가설적 문제 상황에서 보이는 다양한 해결전략을 인지할 수 있는 능력이라 정의하며 개인의 인지적 사고과정을 강조하였다. 즉, 암묵적 으로 내재된 개인의 사회적.인지적 특성을 의미한다.

예를 들면, 어떤 유아들은 사회적 상황에서 대인 간 드러나 는 갈등을 해결하기 위해 폭력을 사용하거나 도구를 사용하 겠다고 말하지만 사회적으로 용인되는 기술을 사용하는 유아 는 갈등을 적절히 견디며 상황을 해결하려는 전략을 제시한 다(Rowlison \& Felner, 1998). 또한 아동기에 사회적 상황에서 필요한 갈등을 해결할 수 있는 능력이 부족하여 겪게 되는 딜 레마나 스트레스는 아동의 심리사회적 부적응과도 연관된다 (J. Kim \& Nahm, 2011). 자녀의 정서표현에 애정적이고 수용 적인 반응을 하는 어머니를 둔 아동은 구조적인 대처반응을 취하나 어머니가 자녀의 정서표현을 억제하고 통제할수록 자 녀는 갈등상황에서 공격적인 반응을 나타내었다(W. J. Park, 2009).

최근 부모의 상위정서 양육방식과 아동의 사회대처기술에 대해, 자녀의 정서에 감정코치 양육방식을 보이는 어머니의 자녀들은 어머니와의 상호작용을 통해 갈등 상황을 조절하고 대처하는 유형을 학습한다고 밝혔다(Katz et al., 2012; LagacéSéguin \& Gionet, 2009). 그러나 정서사회화와 연관된 다수의 선행연구들은 자녀의 부정적 정서에 대한 부모의 반응 혹은 정서신념과 관련하여 아동의 사회정서발달을 살펴본 연구들 은 있으나, 주로 부모의 양육방식 혹은 신념 등으로 단일측면 을 측정하고 있다. 반면 상위정서철학은 어머니가 정서적 경 험에 대해 어떤 가치관을 갖고 있느냐에 따라 신념이 행동으 로 드러나서 자녀와의 관계에서 구체적인 양육행동 및 반응으 로 나타난다고 보았다(Gottman et al., 1997). 예를 들어, 정서를 잘 수용하는 상위정서를 가진 어머니는 자녀와 정서에 관한 이야기를 많이 나누는 온정적인 반응을 보였으나(Ramsden $\&$ Hubbard, 2002), 정서표현을 억제하는 상위정서를 가진 어머 니는 자녀가 느끼는 정서에도 부정적인 반응을 보였다(Choi $\& \mathrm{Min}, 2007)$. 즉 동일한 정서적 상황과 맥락에도 부모마다 느 
끼는 방식과 수용하고 표현하는 정도가 다르며 이는 자녀와의 정서적 상호작용으로 나타나 결국 자녀가 갈등상황을 대처할 수 있는 능력에도 영향을 미치리라 유추할 수 있다. 그리하여 본 연구에서는 어머니의 정서관련행동을 포함하는 상위정서 철학이 자녀의 대인 간 문제해결능력에 어떠한 영향을 미치는 지 살펴보고자 한다.

한편 부모-자녀의 정서적 관계는 자녀의 또래관계와도 밀 접한 관련이 있는데, 부모와 자녀의 정서적 상호작용은 자 녀와의 관계 속에서 의미 있는 양육방식을 통해 이루어지 며 이는 자녀가 맺게 되는 또래 관계 양식에도 영향을 준다 (Gottman et al., 1996, 1997; Gottman \& Nahm, 2007). 가족 맥 락에서 부모-자녀의 정서적 특성과 또래 관계의 관계를 살핀 연구를 보면 아동의 정서에 대한 부모의 지지는 자녀의 사회 적 지위에 연관이 있었고, 부모의 정서 관련 신념체계는 아동 의 또래 관계와 관련된다고 나타났다(Diener, Isabella, Behunin, $\&$ Wong, 2008). 즉 가족이라는 아동의 환경적 맥락에서 발생 하고 경험하는 사회.정서적 경험은 아동의 사회성 발달에 주 요한 요인이 된다고 볼 수 있다.

특히 어머니의 정서사회화 관련 행동들이 자녀의 사회 적 능력과 관련이 있음을 미루어(Eisenberg, Fabes, Shepard, Murphy, \& Reiser, 1999; Eisenberg et al., 2001), 어머니를 통한 아동의 정서사회화는 아동이 형성하는 다양한 사회적 관계를 맺어나가고 유지하도록 하는 환경요인임을 예측해볼 수 있 다. 성숙하게 본인의 정서를 다루는 어머니의 자녀들은 인기 아동으로 지목받는 빈도가 높고 유능한 아이로 평가된 반면 (Katz \& Hunter, 2007; W. J. Park, 2009; Song \& Nahm, 2013), 정서를 자유롭게 수용해주지 않는 어머니를 둔 아동은 비인 기아일 가능성이 높고 놀이 시 비중이 작은 역할을 수행한다 (Song \& Nahm, 2013; Yoon, 2013).

특히 학령전 아동의 핵심적인 발달과업은 아동이 또래관계 에 얼마나 적응적으로 참여하는 것이므로 본 연구에서는 또래 관계를 중점으로 아동의 또래 유능성을 살피고자 하며 아동의 또래 유능성을 또래와 잘 어울리고 관계를 친사회적으로 유지 하며, 주도할 수 있는 능력으로써 효율적이고 긍정적인 기능 의 측면으로 보고자 한다.

또래 유능성과 연관된 부모 변인의 선행연구를 보면, 어머 니의 양육 방식이나 양육태도 및 양육신념(T. E. Kim, 2014; Kwon \& Park, 2003)이 대다수였고, 정서적 신념(M.-H. Park $\&$ Jung, 2012), 어머니의 정서반응태도(Huh, 2003; E.-K. Kim, 2007), 어머니 정서표현성( $\mathrm{Im}, 2009)$ 과 또래 유능성의 관계를 다룬 연구가 그간 주를 이루었다. 이처럼 부모의 정서관련 변
인과 아동의 또래 유능성 간의 관계를 살핀 연구를 보면, 정서 에 합리적이며 온정적인 반응을 보이는 어머니의 자녀는 또래 관계에서 사교적이고 정서적으로 안정적이었으나 정서를 통 제적이고 거부적으로 반응하는 어머니의 자녀는 타인에게 공 격적이고 배려가 부족한 것으로 나타났으며 우울 등의 적응 문제로도 이어졌다(Im, 2009; E.-K. Kim, 2007; Kwon \& Park, 2003). 그러나 위와 같이 선행연구는 어머니의 정서와 관련된 단일차원의 행동에 초점을 두고 있는데, 본 연구에서 부모의 상위정서철학은 당면한 정서적 상황에서 본인이 가진 고유한 신념 및 가치관에 의해 영향을 받는 구체적인 정서관련 양육 태도를 통해 아동의 사회성 발달에 지대한 영향을 미치게 되 는 관계를 살피고자 한다. 또한 또래 유능성은 교사가 하는 평 정이 가장 타당하다는 연구결과를 근거하여(J. Park \& Rhee, 2001) 아동의 담임교사 통해 또래 유능성을 살피고자 한다.

그리하여 본 연구에서는 아동의 구체적인 사회적 행동으로 나타나기 전의 선행 능력인 아동의 대인 간 문제해결능력과 아동이 사회적 장면에서 사회적 행동으로 드러난 또래 유능성 에 영향을 주는 어머니의 상위정서철학의 특성을 함께 탐색하 고자 한다. 이를 통해 아동의 인지.사회발달 및 사회적 적응을 돕기 위한 심리적 중재 시 어머니의 상위정서철학이라는 새로 운 차원의 개입 방향성을 제시하리라 기대한다. 이를 위한 연 구문제는 다음과 같다.

\section{연구문제 1}

어머니의 상위정서철학이 아동의 대인 간 문제해결능력에 미 치는 영향은 어떠한가?

\section{연구문제 2}

어머니의 상위정서철학이 아동의 또래 유능성에 미치는 영향 은 어떠한가?

\section{연구방법}

\section{연구대상}

본 연구에서는 서울, 경기와 인천에 위치한 어린이집과 유치 원 24곳에 다니는 만 4,5 세 아동(남아 32 명, 여아 22명)과 그 들의 어머니 54 쌍과 아동의 기관 담임선생님이 대상으로 참 여하였다. 


\section{연구도구}

\section{어머니의 상위정서철학}

어머니의 상위정서철학은 부모 본인이 경험했거나 경험하 게 되는 정서에 관련한 질문들과 자녀가 경험하는 정서에 대 한 질문들로 구성된 인터뷰를 통하여 부모 자신이 갖고 있는 부정적 정서(슬픔과 분노)에 대한 가치관, 인식방식, 경험, 감 정적 표현 및 자녀가 경험했거나 경험하게 되는 부정적 정서 (슬픔과 분노)에 대한 부모의 인식방식과 신념 및 행동양식 을 면접하여 측정한다. 또한 부모가 정서적 상황에서 자녀가 보이는 정서반응에 대해 적절한 코치를 하는지 여부도 포함 한다. 본 연구는 Katz와 Gottman (1986)이 구조화하고 Nahm (2006)이 번안한 부모의 상위정서 인터뷰(Parent Meta-Emotion Interview [PMEI])를 통해 부모 자신이 경험하는 부정적인 정 서(슬픔과 분노)에 관련한 질문들과 부정적인 정서(슬픔 및 분 노)에 대해 반응하는 자녀를 어떻게 생각하고, 수용하며, 코치 하는지 등을 측정하였다. 개인당 인터뷰는 30-60분 정도로 소 요된다.

인터뷰는 어머니가 이야기한 본인 정서와 자녀 정서에 대 한 상위정서철학의 내용을 분석하기 위해 모두 녹음된 후, 연구자가 상세히 기록한 축어록을 Katz, Mittman과 Hooven (1994)이 제작하고 Nahm (2006)이 번안한 상위정서 코딩체계 (Meta-Emotion Coding System)를 이용하여 분석한다. 상위정 서 코딩체계는 어머니의 상위정서에 대한 인터뷰 내용을 6점 척도로(매우 일치, 일치, 중립, 불일치, 매우 불일치, 알 수 없 음) 코딩하여 수치화할 수 있도록 조직된 체계이다. 평정자 간 신뢰도를 위해 7개월 이상 부모 상위정서인터뷰 코딩훈련을 이수한 연구자 외 아동심리학 석사 1 인(발달심리사 2 급, 청소 년 상담사 2 급)은 전체 데이터의 $30 \%$ 를 교차 분석하였다. 이 를 구체적으로 살펴보면 다음과 같다.

어머니 본인의 정서에 대한 상위정서철학 면접자의 질문 을 통해 어머니는 평상시 본인이 일상생활에서 경험하는 부정 적 정서(슬픔과 분노)에 관련한 느낌이나 관련 경험들을 기술 하게 되고, 이를 측정하기 위해 반 구조화된 인터뷰를 사용한 다. 인터뷰 질문은 "어머니께서는 슬픔에 대해 일반적으로 어 떻게 생각하시나요?” 등이 포함된다. 수집한 인터뷰 자료는 정 서인식(12문항), 정서수용(17문항), 정서조절(12문항)로 분류 된 세부코딩항목에 매우 일치, 일치, 중립, 불일치, 매우 불일 치, 알 수 없음의 6점 척도로 코딩하였다. 정서인식은 "부모는
이 감정과 다른 감정을 구별하는데 어려움이 있다.”, 정서수용 은 “부모는 이 감정을 표현 하는 것에 편안함을 느낀다.", 정서 조절은 “감정의 격렬함을 조절하는 것에 어려움이 있다." 등 의 내용을 포함한다.

각 항목의 점수들은 슬픔과 분노로 각기 나눠 인터뷰된 질 적 내용을 바탕으로 상위정서코딩체계를 통해 점수화된다. 점 수가 산출된 이후에는 산출된 슬픔과 분노 점수가 더해진다. 각 항목별 내적 합치도는 정서인식이 .75, 정서수용이 .71, 정 서조절이 .88이었고 평정자 간 신뢰도는 정서인식이 . 76 , 정서 수용이 .88 , 정서조절이 .93 이었다.

자녀의 정서에 대한 상위정서철학 면접자의 질문을 통해 어머니는 자녀의 정서에 대한 상위정서철학을 기술하게 되고, 여기에는 일상에서 자녀가 처하는 부정적인 정서(슬픔과 분 노)에 대한 어머니의 가치관, 신념 및 태도나 감정 코치 여부 가 포함된다. 이를 측정하기 위해 반구조화된 인터뷰가 사용 된다. 인터뷰 질문은 "자녀가 분노하거나 화를 낼 때, 어머니 는 어떻게 반응하시나요?" 와 같은 질문이 포함된다. 코딩하위 항목들은 자녀의 정서인식(9문항)과 정서수용(13문항), 그리 고 정서코칭(11문항)과 정서조절(9문항)로 분류되며, 정서인 식은 “부모는 자녀가 느끼는 감정의 원인을 안다.", 정서수용 은 “부모는 자녀의 감정을 공감한다.”, 정서코칭은 “부모는 감 정의 본질에 대해 아동과 이야기한다.", 정서조절은 "자녀는 이 감정을 조절하는 것을 힘들어한다.” 등의 내용을 포함한다. 각 코딩항목에 대해 매우 일치, 일치, 중립, 불일치, 매우 불일 치, 알수 없음의 6점 척도로 수치화하여 코딩하였다.

각 항목의 점수들은 슬픔과 분노로 각기 나눠 인터뷰된 질 적 내용을 바탕으로 상위정서코딩체계를 통해 점수화된다. 점수가 산출된 이후에는 산출된 슬픔과 분노 점수가 더해진 다. 각 항목별 내적 합치도는 정서인식이 .66, 정서수용이 .83, 정서코칭이 .90 , 정서조절이 .66이었고 평정자 간 신뢰도는 정 서인식이 .80 , 정서수용이 .88 , 정서코칭이 .89 , 정서조절이 .73 이었다.

\section{아동의 대인 간 문제해결능력}

아동에게 그림으로 가설적인 갈등상황을 제시하여 아동이 각 문제를 해결하기 위해서 얼마나 다양한 해결방법을 생각할 수 있는지를 평가하기 위해 Webster-Strattron과 Hammond (1997) 가 제작하고 Kwon과 Park (2003)이 번안한 대인 간 문제해결 능력 검사(WALLY Social Cognitive Problem Solving Test)를 사 
용하였다. 본 연구에서 수행된 갈등 상황은 친구의 거부 상황, 아동이 실망하게 된 상황, 친구가 괴롭히는 상황, 친구가 놀리 는 상황, 친구의 신체적 공격 상황, 아동의 또래 집단 가입, 친 구와의 딜레마 상황에 대한 것이었다.

면접자는 “지금부터 선생님이랑 $\bigcirc \bigcirc$ 랑 이야기 만들기 게 임을 할 거야. 게임을 위해서 한 가지 규칙이 있어. 그건 $\bigcirc \bigcirc$ 가 그림을 본 후 선생님이 하는 질문에 생각나는 만큼 이야기를 만들어 주면 되는 거야.”라고 아동에게 질문을 하였다. 그림 자료를 놓고 하나씩 보여주며 각 가설적 갈등 상황을 간략히 설명한 뒤 “이럴 때 어떻게 할까? 정답은 없으니 $\bigcirc \bigcirc$ 의 마음에 떠오르는 대로 말해 봐.”라고 한 후, 각 아동이 처하게 되는 각 갈등 상황에 대한 응답은 그대로 수기로 기록되었다.

유아가 기술한 응답은 Y.-J. Kim (2014)이 제시한 응답의 질 적 접근을 따라 5 가지 수준을 나눈 후 분류하여 점수화하였 다. 0-4수준으로 분류되며, 수준별로 각 1-5점의 점수를 얻을 수 있다. 0 수준은 무전략이나 상황부정 및 공상적 이야기를 기 술하는 것으로써 1 점이 적용된다. 1 수준은 미분화된 자기중 심적 사고로 신체 공격/물리적 도구를 사용한 공격, 보복 등의 내용이 포함되며 2점 부여된다. 2수준은 분화되었으나 주관 적인 사고로 자기주장, 새로운 대안 찾기, 고치기 등의 내용이 포함되며 3점이 부여된다. 3수준은 상호적이나 자기욕구를 반영한 사고로 나타나며, 요청, 거래 등의 내용이 포함되어 4 점 부여된다. 4수준은 상호적이며 공동목적추구사고로 양보, 용서, 화해 등의 내용이 포함되어 5점 부여된다. 그 후 아동의 대인 간 문제해결능력은 각 수준별 점수를 총합한 단일점수로 산출된다. 대인 간 문제해결능력이 높은 점수의 아동은 문제 해결전략의 질적 수준이 높다는 것을 뜻하고, 낮은 점수의 아 동은 문제해결전략의 질적 수준이 낮다는 것을 의미한다.

아동의 대인 간 문제해결능력은 각 상황별 점수를 총합한 점수로 산출되며 점수가 높을수록 아동은 대인 간 문제해결능 력이 높음을 의미한다. 아동심리 연구원과 함께 전체 사례의 $30 \%$ 에 해당하는 16 케이스에 대한 평정자 간 일치도는 .94로 나타났다.

\section{아동의 또래 유능성}

또래 유능성을 측정하기 위하여 J. Park과 Rhee (2001)가 제작 한 또래 유능성 척도-교사 평정형을 사용하였다. 본 척도는 타 당화가 검증된 척도로, 기관을 등원하는 만 5, 6세 아동 365명 과 그의 교사 16 명에게 실시되었다.

척도는 세 개의 하위변인인 사교성, 친사회성 그리고 주도
성으로 구성되어 있다. 사교성은 아동이 또래 집단에 수용되 며 다양한 아동과 어울릴 수 있는 능력을 측정한다. 사교성 문 항 중 “또래가 이 아동을 좋아한다.” 등이 있다. 친사회성은 갈 등이 발생 시 친사회적으로 해결하려는 시도를 의미하며 친사 회성 문항 중 "어려움이나 위기에 있는 아이를 잘 도와준다." 등이 있다. 주도성은 또래 집단 속에서 놀이나 활동을 적극적 으로 주도해나가며 자신의 의견을 주장하는 능력을 측정하고 주도성 문항 중 “다른 또래들이 흥미를 갖고 따라할 만한 활동 이나 놀이를 제안한다." 등이 있다.

척도는 총 15 문항으로 사교성, 친사회성, 주도성으로 나누 어지며 전혀 그렇지 않다, 그렇지 않다, 보통이다, 그렇다, 매 우 그렇다의 5점 척도로 되어있다. 각 영역의 점수가 높을수록 사회적으로 유능한 아동임을 뜻한다.

하위요인별 문항 내적 합치도는 사교성은 .93 , 친사회성은 .90 , 주도성은 .93 이었고 아동의 또래 유능성의 총 내적 합치 도는 .88 로 산출되었다.

\section{연구절차 및 분석}

어머니의 상위정서철학 인터뷰 질문지 및 아동의 대인 간 문 제해결능력 도구의 적합성 및 소요시간을 알아보고자 어린이 집 2 곳의 만 4,5 세 아동 각 5 명씩 10 명의 아동 및 그의 어머니 를 예비조사하였다. 어머니들은 모두 무리 없이 질문내용을 기술할 수 있었고 언어발달이 느리고 낮선 이에 대한 경계가 있는 만 4 세의 유아 1 명을 제외하고는 대다수의 유아에게 어 려움 없이 대인 간 문제해결능력 검사를 진행할 수 있었다.

본 조사는 2014년 9월 1일부터 2015년 4월 30일까지 서울 및 경기 지역의 어린이집 및 유치원에 가정통신문 배부를 통 해 연구 참여자를 모집하고 참여를 희망하는 부모에 한해 사 전 확인 전화를 하였다. 아동의 연령 및 기관 담임교사의 협조 를 확인하고 어머니께 사전 동의를 구하여 해당 기관의 담임 교사에게 연구 취지와 과정을 설명하고 협조를 재확인하였다. 교육기관의 환경적 특성을 통제하기 위해 유치원 및 어린이집 에 재원하고 있는 유아만을 대상으로 하였다. 어머니의 상위 정서철학 면접과 아동의 대인 간 문제해결능력 면접은 아동의 가정이나 어머니의 직장으로 직접 방문하여 측정되거나, 아동 이 재원 중인 기관의 동의하 빈 교실에서 면접하였다. 어머니 와 아동의 연구동의서를 받고나서 인터뷰를 녹음하고 면접응 답을 기록한 후 연구소로 가져와 분석하였다. 아동의 또래 유 능성 질문지는 아동의 담임교사가 평정하여 우편으로 회수 받 는 방식으로 실시하였다. 본 연구의 인터뷰자료는 개인의 신 
상 정보가 노출되지 않고 익명성이 보장될 수 있도록 관리되 었고 통계처리 목적으로만 사용되었다.

7개월 간 수집된 아동 총 57 명의 자료 중에서 가정 내 사정 (이민 및 유치원 퇴소)으로 인해 연구에 끝까지 참여하지 못하 게 된 3쌍의 어머니와 자녀를 제외한 54 쌍의 어머니와 자녀를 대상으로 연구분석을 실시하였다.

수집된 자료는 프로그램 PASW Statistics 18.0 (SPSS Inc., Chicago, IL)을 통해 주요 변인 간의 관련성을 살피기 위해 Pearson 적률상관관계 분석을 하였으며, 변인 간의 영향력을 살펴보기 위하여 중다회귀분석을 실시하였다.

\section{연구결과}

\section{연구대상자의 일반적 특성}

본 연구대상자의 일반적 특성은 Table 1 과 같다. 분석 결과, 아 동의 성별을 살펴보면 남아 32 명(59.3\%)가 여아 22 명(40.7\%)

Table 1

Demographic Characteristics

\begin{tabular}{lc}
\hline \multicolumn{1}{c}{ Variable } & Frequency $(\%)$ \\
\hline Gender & $32(59.3 \%)$ \\
Boy & $22(40.7 \%)$ \\
Girl & \\
Child's age & $16(29.6 \%)$ \\
4 & $38(70.4 \%)$ \\
5 & \\
Mother's age & $15(27.8 \%)$ \\
$31-35$ & $29(53.7 \%)$ \\
$36-40$ & $8(14.8 \%)$ \\
$41-45$ & $2(3.7 \%)$ \\
$46-50$ & \\
Mother's education level & $5(9.3 \%)$ \\
High school & $17(31.5 \%)$ \\
College & $25(46.3 \%)$ \\
University & $7(12.9 \%)$ \\
Graduate school and above & \\
Family income a year & $7(13.0 \%)$ \\
$10-25$ million won & $14(25.9 \%)$ \\
25 Million-40 million won & $10(18.5 \%)$ \\
40 Million-55 million won & $15(27.8 \%)$ \\
55 Million-70 million won & $8(14.8 \%)$ \\
70 Million won and above & \\
\hline
\end{tabular}

Note. $N=54$.
보다 다소 높은 비율을 보였다. 아동의 연령은 6세가 16명 (29.6\%), 7세가 38명(70.4\%)으로 나타났다. 어머니의 연령은 36-40세가 53.7\%로 가장 높은 비율을 보였고 31-35세, 41-45 세, 46-50세 순으로 분포되었다. 어머니의 학력은 대학교 졸 업이 $46.3 \%$ 로 가장 많았고, 전문대 졸업 및 대학 중퇴자가, 대 학원 재학 이상, 고등학교 졸업 순으로 나타났다. 어머니 직업 은 무직 및 가정주부가 $46.3 \%$ 로 가장 높은 분포를 보였고 그 다음으로 전문가 및 관련 종사자와 사무종사자, 판매 종사자, 관리자, 서비스 종사자, 기능원 및 관련 기능종사자 순으로 나 타났다. 가정의 월수입은 550-700만원이 $27.8 \%$ 로 제일 많았 으며, 100-250만원이 가장 낮은 분포를 보였다.

어머니의 상위정서철학이 아동의 대인 간 문제 해결능력에 미치는 영향은 어떠한가?

어머니의 상위정서철학이 아동의 대인 간 문제해결능력에 어 떠한 영향력을 미치는지 살펴보기 위해 다중회귀분석 결과 를 Table 2에 제시하였다. 어머니의 상위정서철학은 자녀의 대 인간 문제해결능력에 영향을 미치지 않았다. 자녀에 대한 어 머니의 상위정서철학은 아동의 대인 간 문제해결능력에 미치 는 영향의 설명력은 $30 \%$ 고, 통계적으로 유의한 것으로 회귀 식 모형이 나타났고 $(F=5.22, p<.001)$, 자녀의 정서에 대한 정 서인식이 아동의 대인 간 문제해결능력에 영향을 미치는 것으 로 나타났다 $(\beta=.30, p<.05)$. 그리고 자녀의 정서에 대한 정서 코칭이 자녀의 대인 간 문제해결능력에 영향을 미침이 드러났 다 $(\beta=.51, p<.001)$. 또한 자녀의 정서에 대한 정서조절이 자 녀의 대인 간 문제해결능력에도 영향을 미친다고 $(\beta=.43, p<$ .001) 나타났다. 어머니가 본인의 정서를 인식하고 수용하며 조절하는 것은 자녀가 갈등상황을 해결할 수 있는 능력에 영 향을 미치지 않는 것으로 보고하였다. 반면, 자녀가 경험하는 부정적인 정서에 대해 어머니가 적절하게 인식하고 코칭하며 조절해줄수록 자녀는 또래 관계에서 경험하는 갈등상황에 대 한 해결능력이 높은 것으로 나타났다.

$$
\begin{aligned}
& \text { 어머니의 상위정서철학이 아동의 또래 유능성 } \\
& \text { 에 미치는 영향은 어떠한가? }
\end{aligned}
$$

어머니의 상위정서철학이 아동의 또래 유능성에 어떠한 영 향을 미치는지 알아보기 위한 다중회귀분석 결과는 Table 3 과 같다.

어머니 본인의 정서에 대한 상위정서철학은 또래 유능성에 
Table 2

Multiple Regression Analysis: Maternal Meta-Emotion Philosophy as a Predictor of Interpersonal Problem Solving Ability

\begin{tabular}{|c|c|c|c|c|c|}
\hline Dependent variable & Independent variable & $\beta$ & $t$ & $R^{2}$ & $F$ \\
\hline \multirow[t]{7}{*}{ Interpersonal problem solving ability } & Maternal awareness & .23 & 1.45 & .06 & 1.05 \\
\hline & Maternal acceptance & .01 & .06 & & \\
\hline & Maternal regulation & .05 & .38 & & \\
\hline & Awareness of child's emotion & $.32^{*}$ & 2.46 & .30 & $5.22^{* * *}$ \\
\hline & Acceptance of child's emotion & .29 & -1.04 & & \\
\hline & Coaching of child's emotion & $.51^{* * *}$ & 4.30 & & \\
\hline & Regulation of child's emotion & $.43^{* * *}$ & 3.47 & & \\
\hline
\end{tabular}

Note. $N=54$.

${ }^{*} p<.05 .{ }^{* * *} p<.001$.

Table 3

Multiple Regression Analysis: Maternal Meta-Emotion Philosophy as a Predictor of Child Peer Competence

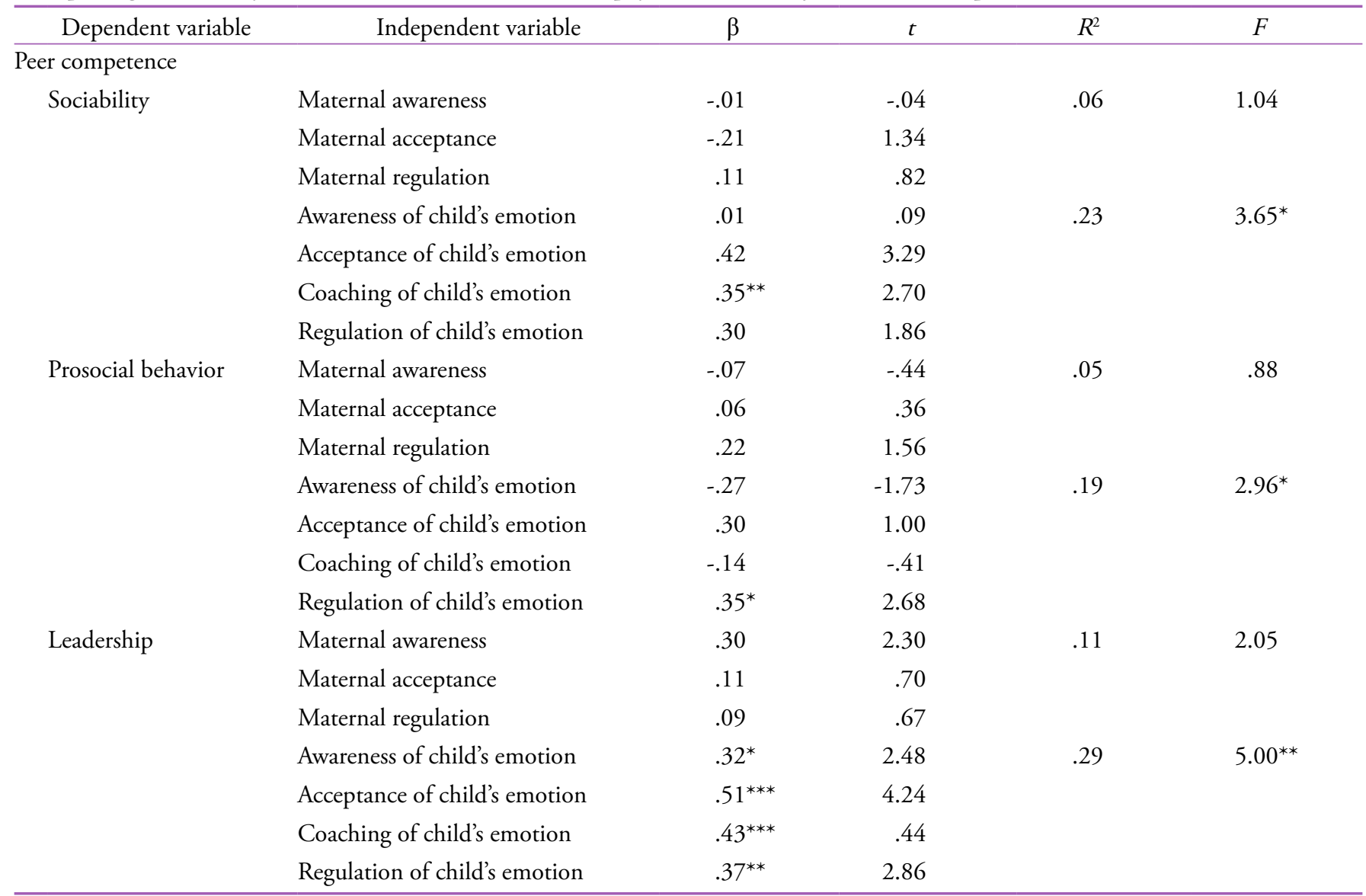

Note. $N=54$.

${ }^{*} p<.05 .{ }^{* *} p<.01{ }^{* * *} p<.001$.

영향을 미치지 않았으나 자녀의 정서에 대한 어머니의 상위정 서철학이 사교성에 미치는 영향의 설명력은 $23 \%$ 고, 통계적으 로 유의한 것으로 회귀식 모형이 나타났고 $(F=3.65, p<.05)$, 자녀의 정서에 대한 정서코칭이 사교성에 영향을 미치는 것
으로 드러났다 $(\beta=.35, p<.01)$. 다음으로 자녀의 정서에 대한 어머니의 상위정서철학이 친사회성에 미치는 영향의 설명력 은 $19 \%$ 고, 회귀식 모형이 통계적으로 유의한 것으로 나타나 $(F=2.96, p<.05)$, 자녀의 정서에 대한 정서조절이 친사회성 
에 영향을 미쳤다 $(\beta=.35, p<.05)$. 자녀의 정서에 대한 어머니 의 상위정서철학이 주도성에 미치는 영향의 설명력은 $29 \%$ 이 고, 회귀식 모형이 통계적으로 유의한 것으로 나타나 $(F=5.00$, $p<.01)$, 자녀의 정서에 대한 정서인식이 주도성에 $(\beta=.32, p$ $<.05)$, 자녀의 정서에 대한 정서수용이 주도성에 $(\beta=.51, p<$ $.001)$, 자녀의 정서에 대한 정서코칭이 주도성에 $(\beta=.43, p<$ $.001)$, 자녀의 정서에 대한 정서조절이 주도성에 $(\beta=.37, p<$ .01 ) 영향을 미치는 것으로 나타났다. 어머니 본인의 정서에 대한 상위정서철학은 자녀가 또래와의 관계에서 보이는 유능 성에 영향을 주지는 않지만, 어머니가 자녀의 정서에 대해서 잘 코칭해줄수록 아동은 또래에게 수용되며 폭넓게 어울리며 리더십이 있고, 어머니가 자녀가 보이는 정서를 잘 조절해줄 수록 자녀는 또래관계를 주도하며 사이좋게 지내고, 어머니가 자녀의 정서를 잘 인식하고 받아줄수록 또래 관계에서 자신의 의견을 효과적으로 주장할 수 있다고 보고하였다.

\section{논의 및 결론}

이 연구는 아동의 심리사회적 발달과 적응에 영향을 미치는 주요한 요인인 어머니의 상위정서철학에 주목하여, 서울시, 경기도, 인천광역시에 거주하는 54 명의 만 4,5 세 아동과 그 어머니를 대상으로 어머니의 상위정서철학과 아동의 대인 간 문제해결능력 및 또래 유능성 간의 관계를 알아보았다. 본 연 구문제를 바탕으로 결과를 요약하고 논의하여 이와 함께 시사 점과 제한점을 제시하고자 한다.

첫 번째로 논의할 결과는, 자녀가 경험하는 부정적 정서를 어머니가 적절히 인식하고 코칭하며 조절해주는 것은 자녀의 대인 간 문제해결능력에 영향을 미친다는 것이다. 이는 부모 와 자녀 간에 정서.사회적 경험이 아동이 사회적 상황을 인지 하는 도식 및 사고과정에 영향을 주는 핵심적인 요인이라 밝 힌 연구(Lemerise \& Arsenio, 2000)와 맥락을 함께 한다. 자녀의 부정적 정서표현을 어머니가 적절히 수용해주고 조절할 수 있 도록 반응하는 것은 아동의 불안한 정서를 어머니가 이해하고 조절할 수 있도록 기여해줌으로 자녀는 정서적 안녕감을 얻 음과 동시에, 어머니의 정서반응을 학습하게 되고(W. J. Park, 2009), 이는 자녀의 정서표현에 대해 어머니가 수용적이고 허 용적인 태도를 보일수록 아동은 문제 상황에서 유연한 대처반 응을 보일 수 있으며, 결국 아동이 원만한 대인관계를 형성하 는데 주요한 요인임을 보여준다.

어떤 부모는 어떻게 하면 정서표현을 사회적으로 바람직
한 범위 내에서 하는 게 옳은건지를 자녀에게 직접적으로 가 르치거나 코칭하기도 한다. 이러한 부모는 자녀가 느낀 정서 경험을 존중하고 설명해주고, 본인의 감정을 이입하여 공감해 줄 수 있으며, 자녀가 직면한 갈등상황을 해결하기 위해 적절 한 제한을 설정해 줌으로서, 자녀가 정서조절을 도울 수 있다 (Gottman et al., 1997; Gottman \& Nahm, 2007). 반면 어떤 부 모는 자녀가 느낀 정서가 해로운 거라 여기며 정서적 상황을 축소시키며 무마하기도 한다. 즉 부모의 정서적 태도 및 행동 들은 부모 자신이 갖고 있는 고유한 상위정서적 태도에 따라 다르게 나타날 수 있으며(Katz \& Hunter, 2007), 어머니-자녀 의 정서적 상호작용을 통하여 자녀가 습득하게 된 정서.사회 적 기술들을 근거로 타인과의 갈등 문제를 해결할 수 있는 자 원을 얻게 되었다고 볼 수 있다.

두 번째로 논의할 것은 자녀의 정서에 대한 어머니의 상 위정서철학이 자녀의 또래 유능성에 유의한 영향을 미쳤다 는 것이다. 이는 어머니가 자녀의 정서표현에 대해 수용적 이고 온정적일수록 아동은 또래 내 관계에서 유능한 것으로 평가받았다는 연구결과(Gottman \& DeClaire, 1997; Song \& $\mathrm{Nahm}, 2013)$ 와 맥을 같이 한다. 그리고 어머니가 자녀의 정서 를 잘 인식하여 코칭해주고 조절하는 것에 도움을 줄수록 아 동에 또래관계 내에서 보이는 주도성도 높은 것으로 나타났 다. 이러한 결과는 부모가 정서코칭 상위정서철학을 보일 때, 아동은 질적으로 높은 수준의 놀이를 하고 낮은 비율의 부정 적 정서표현을 보였다는 연구결과와 일맥상통한다(Katz \& Windecker-Nelson, 2004). 즉 자녀가 슬픔이나 분노의 부정적 인 정서를 경험할 시 어머니가 아이의 마음을 잘 인식하고 수 용하며 감정을 다스리고 조절할 수 있는 교육의 기회를 삼는 상위정서 가치관을 가진 경우, 아동의 유능한 사회성 발달에 긍정적 영향을 미침을 시사하는 바이다. 결국 자녀의 정서에 대한 어머니의 상위정서철학은 자녀가 또래에 수용되어 친사 회적이며 사교적 관계를 맺어나가고 주도하는 또래 유능성과 밀접한 연관이 있음을 보여준다.

한편 본 연구에서는 어머니가 경험하는 본인의 부정적 정 서에 대한 상위정서철학은 아동의 대인 간 문제해결능력 및 또래 유능성에는 어떠한 영향도 주지 않았다. 이는 본인의 정 서를 잘 다루는 부모를 둔 자녀들은 또래에게 인기가 있고 문 제해결능력도 높고(Katz \& Hunter, 2007; Sung, 2013), 사회·정 서적으로 높은 유능감이 있는 아이로 평가된 기존 연구 결과 (Eisenberg et al., 1998)와 일치하지 않는다. 본 연구의 대상인 아동은 만 4,5 세로 학령전기에 속한다. 이 시기 아동은 어머 니의 정서적 특성을 적절히 인지하고 반응할 만큼의 자기중심 
적 조망에서 벗어난 정서.사회발달이 성숙하게 이루어지지 않 은 시기이다. 또한 아동은 부모와의 상호작용에 민감하게 영 향을 받아 정서를 학습해 나가게 되는데, 이때 어머니가 본인 의 정서에 대해 갖고 있는 상위정서철학은 정서관련 신념이나 및 가치관들로 드러나 양육방식에 투영되어 나타날 수 있지 만(Katz et al., 2012), 아동의 또래관계에 직접적인 영향을 주는 정서코칭이나 정서지도를 보이는 방식으로는 드러나지 않기 에 어머니 본인의 정서에 대한 상위정서철학이 자녀의 정서에 대한 어머니의 상위정서철학만큼 자녀와의 관계에 직접적인 연결이 나타나지 않을 수 있다고 추측된다.

위의 결과를 근거하여 본 연구가 지향하는 의의 및 시사점 은 다음과 같다.

첫째, 아동의 정서사회화에 근간이 되는 어머니 상위정서 철학이 아동의 발달에 영향을 미친다는 선행연구들의 결과를 검증한 것에 의의를 가진다. 그간 국내연구를 통해 밝혀진 어 머니의 상위정서철학을 다룬 연구는 대부분 학령기 이후의 아 동 및 청소년을 대상으로 진행되었는데, 본 연구는 어머니 상 위정서철학이 어린 시기의 아동의 사회적 능력 및 기능의 발 달에 초석이 된다는 것을 밝혔다. 무엇보다 이 시기는 어머니 본인의 정서에 대한 경험 및 태도보다는 자녀가 경험하는 정 서에 대해 어머니가 지닌 가치관과 신념들이 아동의 발달에 더 큰 영향력을 미친다는 것을 밝힌 것에 의의가 있다.

둘째, 연구의 객관성과 정확성을 확보하기 위해 연구도구 를 다채롭게 사용하여 질적.양적 연구의 장단점을 보완하는 시도를 하였다. 어머니의 상위정서철학은 장기간 전문 훈련을 받은 면접자와 어머니와의 일대일 면접을 통해 정서적 경험들 에 관련한 질적 정보들을 수치화하여 양적으로 분석하였다. 아동의 대인간 문제해결능력은 면접자와 아동 간의 일대일 면 접을 통해 보다 전문적인 평가를 이루는 시도를 하였고, 아동 의 또래 유능성은 교사평정방법을 통해 보다 객관적인 시각으 로 유능성을 평정할 수 있도록 하였다.

셋째, 아동의 사회인지발달 및 사회성 발달에 주요한 영향 을 주는 요인인 어머니의 상위정서철학에 대해 밝혔다. 그간 어머니의 상위정서철학과 아동의 사회인지발달과 사회성 발 달 간의 관계를 함께 탐색한 연구는 거의 없었다. 본 연구는 자 녀의 또래관계 뿐만 아니라 사회인지능력에까지 영향을 주는 어머니의 상위정서철학의 영향력을 밝혀냄으로 다양한 발달 영역 성장에 기초가 되는 어머니의 상위정서철학의 효과를 기 대한다.

타인과의 관계에서 취약성을 보이는 아동의 사회성을 향상 시키고 수정하기 위해 성인의 개입을 통한 많은 양의 시간이
필요로 한다는 연구로(Webster-Stratton \& Reid, 2003)로 미루 어 봤을 때, 아동의 사회성에 큰 영향을 주는 어머니의 상위정 서철학을 다루는 심리중재프로그램의 개발이 시급하다.

끝으로 본 연구의 제한점을 바탕으로 후속연구가 보완해야 할 점은 다음과 같다. 첫째, 면접법을 사용함으로 발생한 시간 과 비용의 문제로 표집크기가 적어 연구결과를 일반화하는 것 에 한계가 있다. 후속연구에서는 표집 크기를 늘려 인구사회 학적 변인의 특성이 균형 있게 반영된 연구가 이뤄질 필요가 있다.

둘째, 어머니의 상위정서철학을 슬픔과 분노를 나누어 살 피지 않았고 부정적 정서라는 단일차원으로 살펴보았다. 그러 나 슬픔과 분노라는 부정적 정서에 대해 반응하는 어머니의 태도가 각각 달랐다고 보고한 연구(J. Kim \& Nahm, 2013)로 미루어보아, 각기 정서 유형별로 상위정서철학을 탐색하는 연 구가 진행될 필요가 있다.

셋째, 본 연구에서는 기관 교사와 같은 아동을 주변 환경에 놓인 의미 있는 사회적 타인의 영향력을 고려하지 않았다. 특 히 아동과 많은 시간을 보내게 되는 교사는 직접적인 모델링 의 대상이 되며, 아동은 교사를 관찰학습하게 되므로 교사가 지닌 정서에 대한 상위정서철학은 아동의 발달에 다양한 영향 을 미칠 거라고 유추해볼 수 있다. 그러나 국내에서 교사의 상 위정서철학 연구는 전무한 실정이기에 이를 탐색할 후속연구 가 진행될 필요가 있다. 요약하면 아동의 사회.정서적 능력을 지원하는 사회적 자원으로서 교사의 상위정서철학에 관련한 교육 및 연수 프로그램 개발이 시급하다는 것을 함의하며 본 결과가 기초자료를 제공할 수 있기를 바란다.

\section{Notes}

This article is a part of the first author's master thesis submitted in 2015, and was presented as a poster at the 2015 Annual Fall Conference of the Korean Association of Child Studies.

\section{Conflict of Interest}

No potential conflict of interest relevant to this article was reported. 


\section{References}

\section{In English}

Diener, M., Isabella, R., Behunin, G., \& Wong, M. (2008). Attachment to mothers and fathers during middle childhood: Associations with child gender, grade, and competence. Social Development, 17(1), 84-101. doi:10.1111/j.1467-9507.2007.00416.x

Eisenberg, N., Cumberland, A., \& Spinrad, T. L. (1998). Parental socialization of emotion. Psychological Inquiry: An International Journal for the Advancement of Psychological Theory, 9(4), 241-273. doi:10.1207/s15327965pli0904_1

Eisenberg, N., Fabes, R. A., Shepard, S. A., Murphy, B. C., \& Reiser, M. (1999). Parental reactions to children's negative emotions: Longitudinal relations to quality of children's social functioning. Child Development, 70(2), 513-534. doi:10.1111/1467-8624.00037

Eisenberg, N., Losoya, S., Fabes, R. A., Guthrie, I. K., Reiser, M., Murphy, B., . . Padgett, S. J. (2001). Parental socialization of children's dysregulated expression of emotion and externalizing problems. Journal of Family Psychology, 15(2), 183-205. doi:10.1037/0893-3200.15.2.183

Gottman, J. M., \& DeClaire, J. (1997). The heart of parenting: How to raise an emotionally intelligent child. New York: Simon \& Schuster.

Gottman, J. M., Katz, L. F., \& Hooven, C. (1996). Parental metaemotion philosophy and the emotional life of families: Theoretical models and preliminary data. Journal of Family Psychology, 10(3), 243-268. doi:10.1037/08933200.10.3.243

Gottman, J. M., Katz, L. F., \& Hooven, C. (1997). Meta-emotion: How families communicate emotionally. Mahwah, NJ: Lawrence Erlbaum Associates.

Gottman, J. M., \& Nahm, E. Y. (2007). Raising an emotionally intelligent child: The heart of parenting. Seoul: Hankyung BP.

Katz, L. F., \& Hunter, E. C. (2007). Maternal meta-emotion philosophy and adolescent depressive symptomatology. Social Development, 16(2), 343-360. doi:10.1111/j.14679507.2007.00388.x

Katz, L. F., Maliken, A. C., \& Stettler, N. M. (2012). Parental meta-emotion philosophy: A review of research and theoretical framework. Child Development Perspectives, 6(4), 417-422. doi:10.1111/j.1750-8606.2012.00244.x

Katz, L. F., \& Windecker-Nelson, B. (2004). The child/adolescent meta-emotion coding system. Unpublished manuscript, University of Washington, Seattle, WA.

Lagacé-Séguin, D. G., \& Gionet, A. (2009). Parental metaemotion and temperament predict coping skills in early adolescence. International Journal of Adolescence and Youth, 14(4), 367-382. doi:10.1080/02673843.2009.9748015

Lemerise, E. A., \& Arsenio, W. F. (2000). An integrated model of emotion processes and cognition in social information processing. Child Development, 71(1), 107-118. doi:10.1111/1467-8624.00124

Nahm, E.-Y. (2006). A cross-cultural comparison of Korean American and European American parental meta-emotion philosophy and its relationship to parent-child interaction (Doctoral dissertation). Retrieved from https://www.researchgate.net/ publication/33519650

Ramsden, S. R., \& Hubbard, J. A. (2002). Family expressiveness and parental emotion coaching: Their role in children's emotion regulation and aggression. Journal of Abnormal Child Psychology, 30(6), 657-667. doi:10.1023/ A:1020819915881

Rowlison, R. T., \& Felner. R. D. (1998). Major life events, hassles, and adaptation in adolescence: Confounding in the conceptualization and measurement of life stress and adjustment revisited. Journal of Personality and Social Psychology, 55(3), 432-444. doi:10.1037/00223514.55.3.432

Shortt, J. W., Stoolmiller, M., Smith-Shine, J. N., Eddy, J. M., \& Sheeber, L. (2010). Maternal emotion coaching, adolescent anger regulation, and siblings' externalizing symptoms. Journal of Child Psychology and Psychiatry, 51(7), 799-808. doi:10.1111/j.1469-7610.2009.02207.x

Shure, M. B. (1982). Interpersonal problem solving: A cog in the wheel of social cognition. In F. Serafica (Ed.), Social cognitive development in context (pp. 133-166). New York: Guilford Press.

Stettler, N., \& Katz, L. F. (2014). Changes in parents' metaemotion philosophy from preschool to early adolescence. Parenting, 14(3-4), 162-174. doi:10.1080/15295192.2014. 945584

Webster-Stratton, C., \& Hammond, M. (1997). Treating children with early-onset conduct problems: A comparison of child and parent training interventions. Journal of Consulting and Clinical Psychology, 65(1), 93-109. doi:10.1037/0022006X.65.1.93

Webster-Stratton, C., \& Reid. M. J. (2003). Treating conduct problems and strengthening social and emotional competence in young children. Journal of Emotional and Behavioral Disorders, 11(3), 130-143. doi:10.1177/106342 66030110030101

\section{In Korean}

Choi, H. Y., \& Min, K. H. (2007). The study on the validation of Ambivalence over Emotional Expressiveness Questionnaire: 
Comparison of suppression constructs in Korean culture. Korean Journal of Social and Personality Psychology, 21(4), 71-89. Retrieved from http://www.dbpia.co.kr/

Huh, A. S. (2003). Mother's attitude toward children's expressiveness and children's emotional regulation to peer competence (Master's thesis). Retrieved from http://www.riss.kr/ link?id=T10212888

Im, H. J. (2009). Effect of mother's emotional expressiveness on children's self-concept and children's peer competence (Master's thesis). Retrieved from http://www.riss.kr/ link?id=T11786450

Kim, E.-K. (2007). Preschoolers' peer competence model based on preschoolers' emotional ability and mothers' attitude toward children's emotional expressiveness (Doctoral dissertation). Retrieved from http://www.riss.kr/link?id=T10998324

Kim, J., \& Nahm, E.-Y. (2013). Relations between mother-child communication and the quality of peer relationship. The Journal of the Korean Association of Psychotherapy, 5(2), 3549. Retrieved from http://www.newnonmun.com/

Kim, J. Y., \& Nahm, E.-Y. (2011). The relationship between parental response to children's negative emotion and children's stress-coping behavior: The mediating effects of self-regulation. Korean Journal of Child Studies, 32(5), 1328. Retrieved from http://childstudies.org/journal/view. php?number $=3353$

Kim, T. E. (2014). The effects of emotional understanding and interpersonal problem solving strategies on peer competence of young children (Master's thesis). Retrieved from http://www. riss.kr/link?id=T13538878

Kim, Y.-J. (2014). The effect of the philosophical research group activity by using picture books on the same age group's problem solving skills (Master's thesis). Retrieved from http://www. riss.kr/link?id=T13443585

Kwon, Y. H., \& Park, K. J. (2003). Effects of emotionality, interpersonal problem solving strategies, and maternal behaviors on children's social competence. Korean Journal of Child Studies, 24(3), 27-44. Retrieved from http://kiss. kstudy.com/

Park, J., \& Rhee, U. (2001). Development of a peer competence scale for preschool children. Family and Environment Research, 39(1), 221-232.

Park, M.-H., \& Jung, Y. (2012). Children's goal orientation according to the goal orientation and parenting behavior of their parents. The Korean Journal of Human Development, 19(1), 123-141.

Park, W. J. (2009). The relationship among maternal attitude toward child's emotional expressiveness, children's social perspectivetaking ability and children's coping strategies (Master's thesis). Retrieved from http://www.riss.kr/link?id=T11576513

Song, S.-J., \& Nahm, E.-Y. (2013). Relations between maternal meta-emotion philosophy and children's social competence: Focused on the mediation effects of children's metaemotion philosophy. The Korean Journal of Developmental Psychology, 26(3), 1-17.

Sung, T. H. (2013). Relationships between maternal meta-emotion philosophy, children's ambivalence over emotion expressiveness and severity of depression (Master's thesis). http://www.riss. $\mathrm{kr} /$ link?id=T13231975

Yoon, H. R. (2013). The relations between maternal meta-emotion philosophy and children's interactive peer play perceived by mother and teacher (Master's thesis). Retrieved from http:// www.riss.kr/link?id=T13068118

\section{ORCID}

$\begin{array}{ll}\text { Ranyi Choi } & \text { http://orcid.org/0000-0001-9673-0937 } \\ \text { Eunyoung Nahm } & \text { http://orcid.org/0000-0002-5717-7961 }\end{array}$

Received April 30, 2016

Revision received August 9, 2016

Accepted August 12, 2016 